\title{
Application of Energy-Saving for an inverter feeds three-phase induction motor
}

\author{
Mohamed I. Mosaad ${ }^{1}{ }^{a}$ \\ ${ }^{1}$ Electrical and Electronics Dept., Yanbu Industrial College \\ Keywords: induction motor, energy saving, voltage control \\ https://doi.org/10.53370/001c.29146
}

Yanbu Journal of Engineering and Science

Vol. 18, Issue 1, 2021

Three-phase induction motors are the most prevalent AC motors used in many applications. Operation of these motors at load power less than that of the motor full-load power leads to significant power losses and reduces the motor's efficiency. To mitigate these losses and increase the efficiency of the three-phase induction motors at light loading conditions, energy-saving techniques should be utilized. This paper investigates a voltage control technique applied to light-loaded induction motors to save the energy using an inverter. The light load selected in this paper is a fan load of power load less than the motor full load power. Theoretical analysis, computed characteristics, and experimental verifications are presented to show the effectiveness of the proposed energy-saving technique.

\section{List of symbols}

\begin{tabular}{|l|l|}
\hline$R_{m}$ & iron loss phase resistance \\
\hline$X_{1}$ & stator phase leakage reactance. \\
\hline$X_{2}$ & $\begin{array}{l}\text { rotor phase leakage reactance at standstill } \\
\text { referred to stator. }\end{array}$ \\
\hline$X_{m}$ & phase magnetizing reactance. \\
\hline$I_{1}$ & stator phase current. \\
\hline$I_{2}$ & rotor phase current referred to stator. \\
\hline$I_{0}$ & load phase current. \\
\hline$I_{0 a}$ & equivalent iron loss phase current. \\
\hline$I_{m}$ & phase magnetizing current. \\
\hline$E_{1}$ & stator phase e.m.f. \\
\hline$E_{2}$ & rotor phase e.m.f. \\
\hline$E_{20}$ & rotor phase e.m.f. at standstill referred to stator. \\
\hline$V_{1}$ & input phase voltage. \\
\hline$S$ & slip \\
\hline
\end{tabular}

\section{INTRODUCTION}

Electrical machines consume most of the world's electrical energy annually. Induction motors are the most common type of motors used in industry as they are robust, simple structure, reliable, low cost, and easy to maintain. Induction machines were used as motors and found numerous usage as generators, especially in wind energy conversion systems. Both types of induction generators, self-excited and wound rotor types, were presented in many wind energy applications. This usage is due to their advantages, including self-excited and ease of maintenance in the self-excited type and the ability of operation under variable wind speed for the wound rotor type. ${ }^{1-4}$

Induction motor drive control and estimate is a broad area, and technology has evolved in recent years. Induction motor drives are used in the industry for variable speed applications instead of DC motors. These applications include pumps, fans, electric vehicles, rolling mills, etc. In addition to variable frequency, the drive is getting much attention nowadays, process control for energy saving aspects by variable frequency. Many energy-saving techniques are available for induction motor drives. ${ }^{5}$

Improving the efficiency of electrical drives is essential not only for energy saving but also for preserving the environment. Methods for improving induction motor efficiency are nowadays in the center of interest of many researchers. ${ }^{6-9}$

An investigation for energy saving in three-phase induction motor driving pump load and proposed model control was developed. The model considers inverter voltage harmonics and magnetic saturation effects. ${ }^{10}$

A new effective optimization method was presented on an induction motor control that does not require extra hardware and is sensitive to motor parameters. The relationship between the minimum stator current and the minimum loss in the vector control system was investigated by Li et al. ${ }^{11}$ 
In Vaez-Zadeh and Hendi ${ }^{12}$ an online efficiency optimization controller was proposed for induction motor drives after a detailed analysis of motor losses. The controller searches for minimum motor input power, which continuously varies the control variable, resulting in smooth system performance.

Efficiency optimization control strategies for threephase induction motors with a Hall sensor based on a DSP controller were developed. ${ }^{13}$ The control scheme has been verified by computer simulation based on the proposed model.

In Mirzaeva and Sazdanoff ${ }^{14}$ the effect of flux optimization on energy efficiency of AC drives was discussed. The focus of the study was flux optimization as a part of VSD drive control of induction motors, specifically for fan and pump applications. The detailed motor model presented flux optimization results for various speed and load scenarios and translated these results into practical power savings.

An optimized model was developed to reach higher energy efficiency. ${ }^{15}$ The optimization procedure is based on the analytical model of the machine.

In Sarhan ${ }^{16}$ a new control scheme based on search method taking advantage of the fact that at a certain torque and speed (operating point) there was only one value of stator voltage that operates the motor at optimum efficiency.

Santos et al. ${ }^{17}$ described a method for improving the efficiency of three-phase induction motor drives across the whole operating range. The consequences of magnetic saturation were taken into account when using direct fieldoriented control of induction motors. The non-linear magnetization curve of the iron core was used to mimic the magnetic saturation effect in the machine. The optimal reference rotor flow for vector control was predicted using artificial neural networks.

A control strategy was presented to execute energy savings of three-phase induction motors when they operate under long-term light-load or small duty ratio load. ${ }^{18}$ The proposed technique was based on the notion of constantspeed variable voltage control (VVC). It was created as an energy-saving controller for three-phase induction motors.

A control system architecture for a light electric vehicle's variable voltage and frequency induction motor drive was described in Redgate et al. ${ }^{19}$ The algorithms described will give the supply voltage and frequency required to meet mechanical demand at maximum efficiency using Microsoft Excel, a widely available software tool.

In Redgate et al. ${ }^{19}$ a control system ethos for a variable voltage and frequency induction motor drive for a light electric vehicle was described. Algorithms presented use Microsoft Excel, a readily accessible software package, give the supply voltage and frequency required to meet mechanical demand at maximum efficiency.

\section{METHOD OF ANALYSIS}

Figure 1 shows the full-bridge inverter fed three-phase induction motor driving a fan load

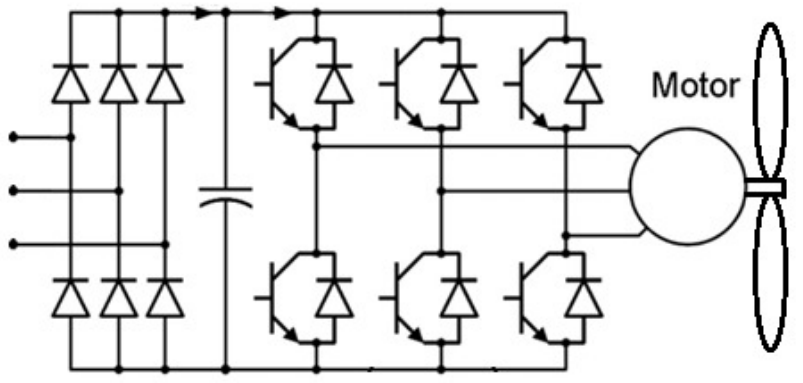

Fig. 1. The proposed system

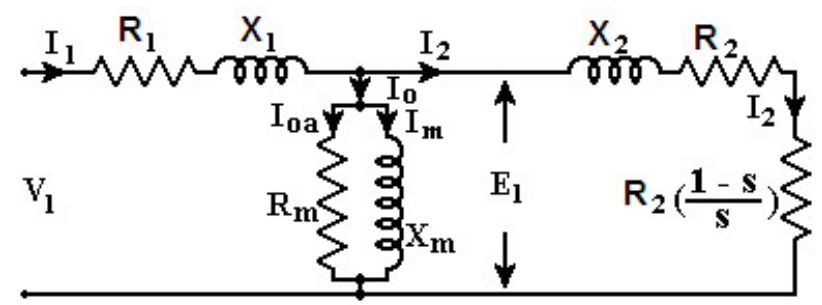

\section{Fig. 2. Equivalent circuit of 3- $\Phi$ induction motor}

The performance of three-phase induction motor is explained with the help of equivalent motor circuit Fig. 2 .

The rotor impedance $Z_{2}^{/}$is calculates as:

$$
Z_{2}^{\prime}=\frac{R_{2}^{\prime}}{S}+j X_{2}^{\prime}
$$

The core equipment impedance can be defined as:

$$
Z_{m}=\frac{R_{m} \times j X_{m}}{R_{m \times}+j X_{m}}
$$

The total rotor impedance can be defined as:

$$
Z_{2 t}=\frac{Z_{m} \times Z_{2}^{\prime}}{Z_{m}+Z_{2}^{l}}
$$

Then the input impedance

$$
Z_{i}=Z_{2 t}+Z_{1}
$$

The input current is

$$
I_{\text {in }}=\frac{V_{1}}{Z_{i}}
$$

The power input to the motor is

$$
\begin{gathered}
P_{\text {in }}=\sqrt{3} V_{1} I_{\text {in }} \cos (\emptyset) \\
P_{\text {in }}=3 V_{1} I_{\text {in }} \cos \varphi_{1}
\end{gathered}
$$

And the efficiency of the motor is obtained from the relation:

$$
\eta=\frac{p_{\text {out }}}{p_{\text {in }}}
$$

These equations are used to determine the motor characteristics and the appropriate voltage control at light loading conditions.

\section{COMPUTED CHARACTERISTICS}

This section indicates the actual steady-state motor characteristics at continuous fan operation at any speed as the fan can operate at any speed through any period. 


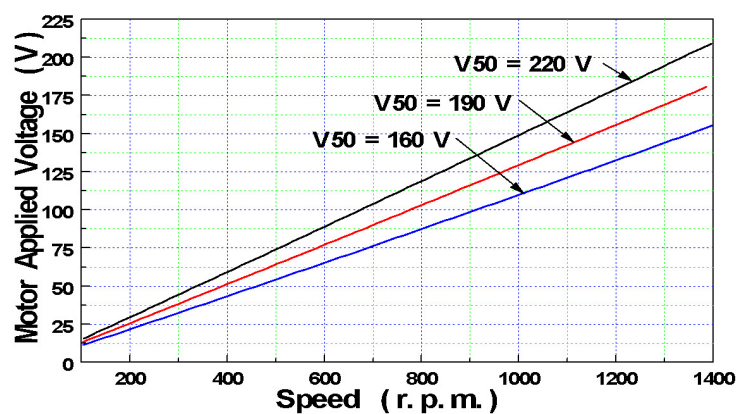

Fig. 3. Variation of the motor's applied voltage as a function of rotor speed (Computed).

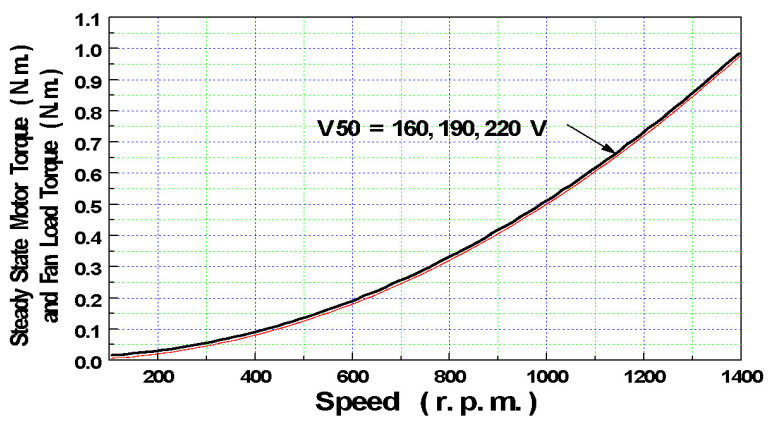

Fig. 4. The variation of steady-state torque and load torque in terms of speed (Computed).

Fig. 3 shows the variation of motor applied voltage with respect to rotor speed. The motor speed is increased by the variation of motor frequency from zero to $50 \mathrm{~Hz}$.

Fig. 4 shows the variation of steady-state motor torque and load torque in terms of speed for different values of motor applied voltage. Both motor and load torque do not vary by these motor voltage variation.

The curves of the input current in terms of rotor speed at different values of supply voltage are illustrated in Fig. 5 . It is seen from the figure that for each value of supply voltage, the minimum input current is occurred at a low speed.

Fig. 6 depicts the variation of the input power as a function of the speed. It is noticed from the figure that the input power is increased as speed increases by approximately cubic ratio.

The output power variation versus speed at different supply voltages is given in Fig. 7. The output power increases as speed increases by a cubic ratio. There is no difference in voltage variation due to the same load torque.

Fig. 8 shows the values of the efficiency for different speeds and terminal voltages. The efficiency increases as the motor speed increases. The efficiency decreases as the supply voltage increases.

Fig. 9 illustrates the variation of motor power factor against the speed at different voltages $(220 \mathrm{~V}, 190 \mathrm{~V}, 160 \mathrm{~V}$, respectively).

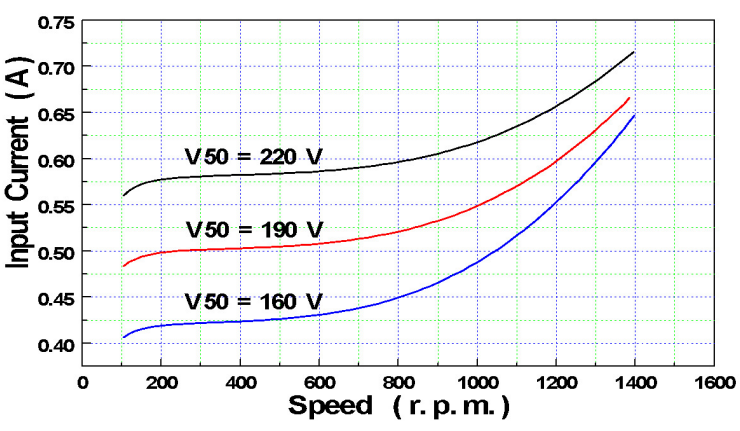

Fig. 5. Variation of input current with rotor speed (Computed).

\section{EXPERIMENTAL CHARACTERISTICS}

Fig. 10 shows the variation of motor applied voltage with speed, when the voltage at $50 \mathrm{~Hz}$ is $190,200,210$, and 220 V. The proposed system is tested in order to evaluate its performance at different values of applied voltage and frequency.

Fig. 11 illustrates the variation of frequency with the motor speed at different values of voltage $(220 \mathrm{~V}, 210 \mathrm{~V}, 200$ $\mathrm{V}$ and $190 \mathrm{~V}$, respectively).

Fig. 12 shows the variation of motor input current versus speed at different values of applied voltage. It is noted that the higher values of input current are associated with higher input voltages at the same motor speed.

Fig. 13 shows the variation of input power with motor speed at different values of applied voltages.

It is vital to note that decreasing the applied voltage reduces the input power. Due to the same load torque curve, the motor output power remains constant at any speed value. As a result, no variation in applied voltage affects the motor output power. This means that the reduction of applied voltage improves the motor efficiency. Or energy saving is obtained by the reduction of motor applied voltage. This will be occurred until the motor torque can operate the load.

Fig. 14 shows the variation of motor power factor with speed at different values of applied voltages.

\section{CONCLUSION}

There are many applications and loading conditions of three-phase induction motors that are not operating at the rated load. Such loading conditions increase the losses and decrease the efficiency of the moors. This paper succeeded at applying an effective energy-saving technique for lightloaded motors by voltage control. This voltage control reduces the motor's input power to fit the load power by vector control of an inverter feeding the motor. A fan load is selected as a light load with variations in its speed. The proposed energy-saving technique-based inverter control reduces the input power to fit the output power while decreasing the losses and increasing the efficiency. 


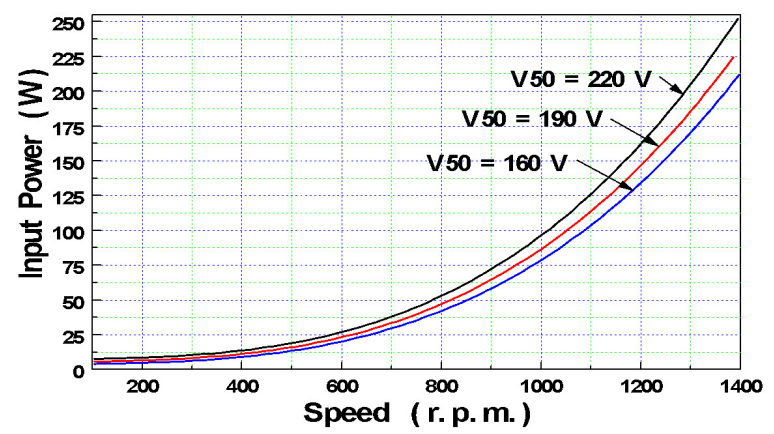

Fig. 6. Variation of the input power with speed (computed).

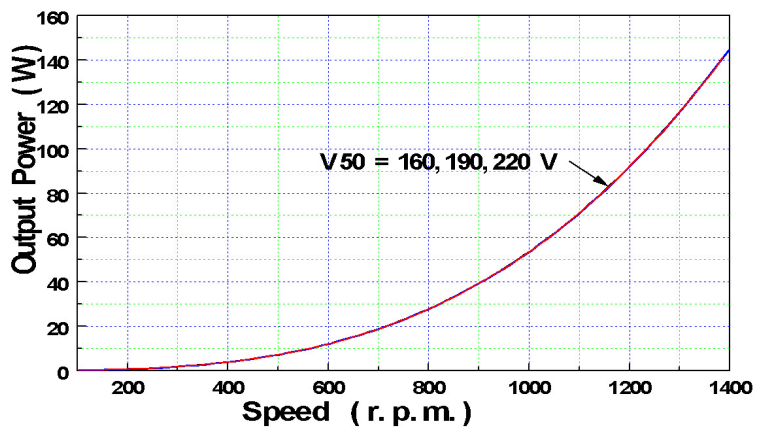

Fig. 7. Variation of output power with rotor speed (Computed).

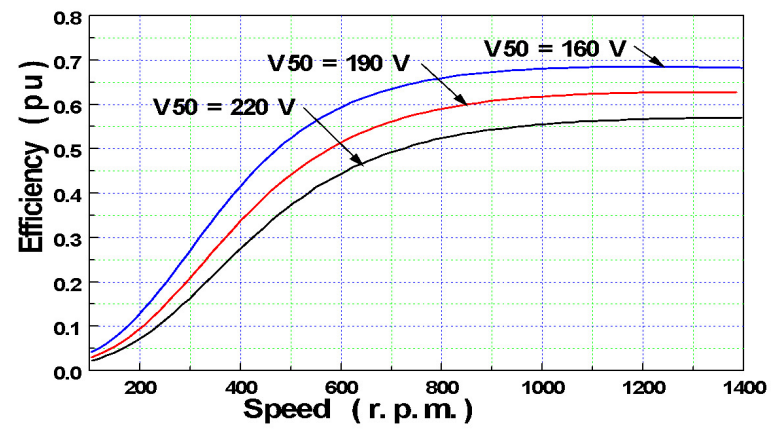

Fig. 8. The values of motor efficiency at different speeds for different values of motor voltages (Computed).

Experimental results proved the simulation results presented in the paper.

Submitted: September 22, 2021 AST, Accepted: October 11, 2021 AST 


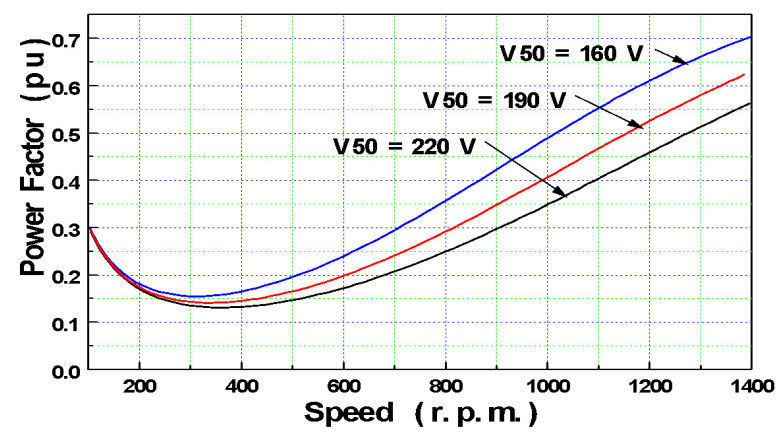

Fig. 9. Variation of motor power factor with speed (Computed).

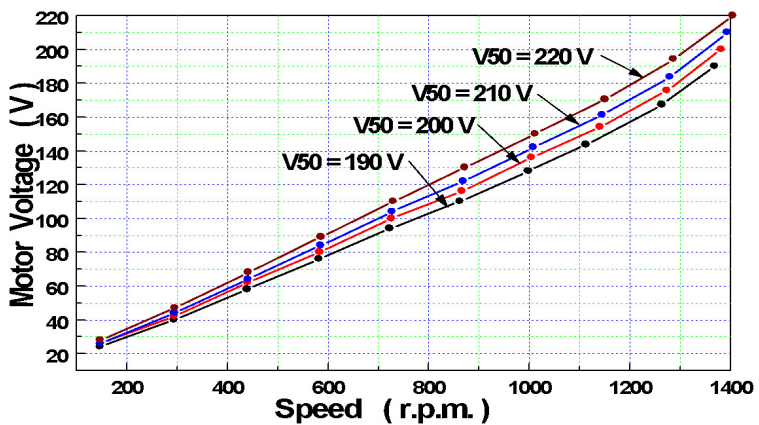

Fig. 10. Variation of motor applied voltage with speed (Experimental).

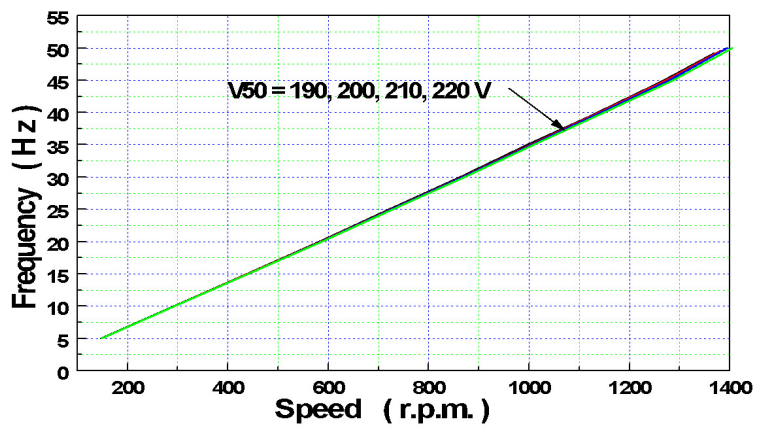

Fig. 11. Variation of frequency with speed (Experimental). 


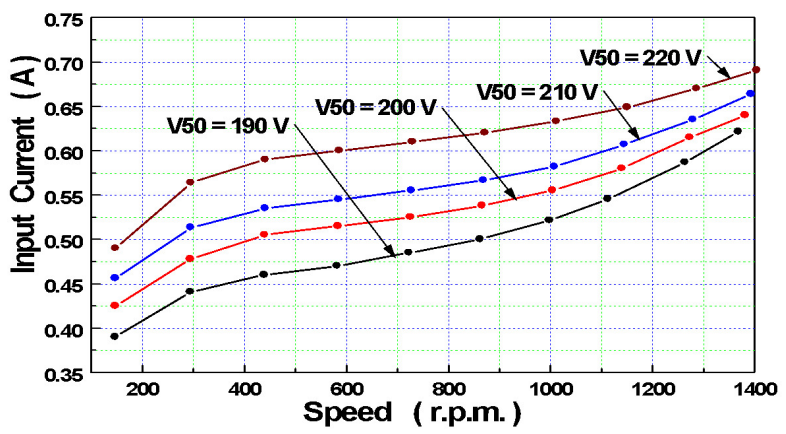

Fig. 12. Variation of input current versus motor speed (Experimental).

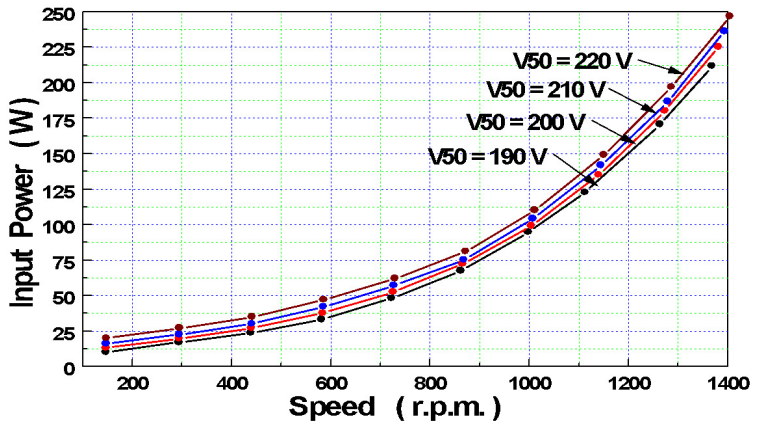

Fig. 13. Variation of input power with motor speed (Experimental).

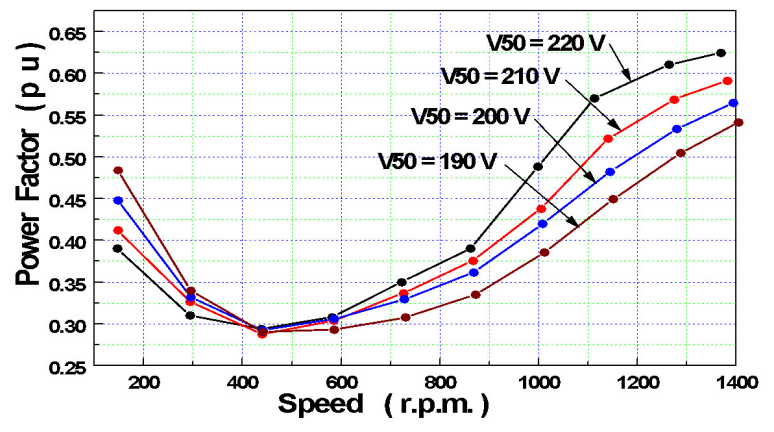

Fig. 14. Motor power factor variation with speed at different values of applied voltage (Experimental).

This is an open-access article distributed under the terms of the Creative Commons Attribution 4.0 International License (CCBY-4.0). View this license's legal deed at http://creativecommons.org/licenses/by/4.0 and legal code at http://creativecommons.org/licenses/by/4.0/legalcode for more information. 


\section{REFERENCES}

1. Mosaad MI, Abu-Siada A, Ismaiel MM, Albalawi H, Fahmy A. Enhancing the Fault Ride-through Capability of a DFIG-WECS Using a HighTemperature Superconducting Coil. Energies. 2021;14(19):6319. doi:10.3390/en14196319

2. Mosaad MI, Alenany A, Abu-Siada. Enhancing the performance of wind energy conversion systems using unified power flow controller. IET Generation, Transmission and Distribution. 2020;14(10):1922-1929.

3. Mosaad MI, Ashmawy MG, Osman ASAE, Zaki MAE. Power quality improvement of WEGCS using STATCOM-based EC techniques. Int J of Industrial Electronics and Drives. 2017;3(4):229-237. doi:10.150 4/ijied.2017.10008453

4. Yunus AMS, Abu-Siada A, Mosaad MI, Albalawi H, Aljohani M, Jin JX. Application of SMES Technology in Improving the Performance of a DFIG-WECS Connected to a Weak Grid. IEEE Access. 2021;9:124541-124548. doi:10.1109/access.2021.3110 $\underline{995}$

5. Inoue K, Asano Y, Kotera K, Kato T. Optimal energy saving trajectories of induction motor with suppression of sudden acceleration and deceleration. In: IEEE Energy Conversion Congress and Exposition (ECCE). ; 2014:32019-33223.

6. Abdelfattah H, Mosaad MI, Ibrahim NF. Adaptive Neuro Fuzzy Technique for Speed Control of Six-Step Brushless DC Motor. IJEEI. 2021;9(2):302-312. doi:1 0.52549/ijeei.v9i2.2614

7. Ta-Cao M, Hori Y. Convergence improvement of efficiency- optimization control of induction motor drives. IEEE. Published online 2000:1662-1669.

8. Ferreira FJTE, de Almeida AT, Baoming G, Faria SP, Marques JM. Automatic change of the stator-winding connection of variable-load three-phase induction motors to improve the efficiency and power factor". IEEE International Journal on Industrial technology, Hong Kong. Published online 2005:1331-1336.

9. Prakash V, Baskar S, Sivakumar S, Sri Krishna K. A novel efficiency improvement measure in three-phase induction motors, its conservation potential and economic analysis. Energy for Sustainable Development. 2008;12(2):78-87. doi:10.1016/s0973-08 26(08)60431-7
10. Ebrahim OS, Algendy AS, Badr MA, Jain PK. ANNbased optimal energy control of induction motor in pumping applications. In: 2009 IEEE Electrical Power \& Energy Conference (EPEC). IEEE; 2009:1-7. doi:10.1 109/epec.2009.5420914

\section{Li J, Xu L, Zhang Z. A New Efficiency} Optimization Method on Vector Control of Induction Motors. In: IEEE International Conference on Electric Machines and Drives. IEEE; 2005:1995-2001. doi:10.11 $\underline{\text { 09/iemdc.2005.195993 }}$

12. Vaez-Zadeh S, Hendi F. A continuous efficiency optimization controller for induction motor drives. Energy Conversion and Management. 2005;46(5):701-713. doi:10.1016/j.enconman.2004.0 $\underline{5.006}$

13. Wang X, Meng D, Xu Y. Efficiency Optimization Control for Three-Phase Induction Motors with Hall Sensor". International Journal of Control and Automation. 2015;8(1):1-8.

14. Mirzaeva G, Sazdanoff L. The effect of flux optimization on energy efficiency of induction motors in fan and pump applications. Presented at: IEEE Australasian Universities Power Engineering Conference (AUPEC); September 2015; Wollongong, Australia. https://doi.org/10.1109/aupec.2015.732486 $\underline{7}$

15. Irimie DL, Radulescu MM, Lar I. Energy-efficiency optimization of small cage-induction motors. In: International Aegean Conference on Electrical Machines and Power Electronics and Electromotion, Joint Conference. IEEE; 2011:556-561. doi:10.1109/acemp.2 011.6490659

16. Sarhan H. Energy efficient control of three-phase induction motor drive. Energy and Power Engineering. 2011;3(2):107-112. doi:10.4236/epe.2011.32014

17. Santos AF, Neves FAS, Aquino RRB. Marcelo C.Cavalcanti "Application of artificial neural network in the efficient control of three-phase induction motor." In: Brazilian Power Electronics Conference (COBEP). IEEE; 2009:159-166.

18. Xue XD, Cheng KWE. An energy-saving scheme of variable voltage control for three-phase induction motor drive systems. 2nd International Conference on Power Electronics Systems and Application. Published online 2006:241-243. 
19. Redgate JS, Kansara M, Holmes PG. Improved efficiency of variable frequency induction motor drives by voltage control. 9th International Conference on Electrical Machines and Drives. 1999;(468):199-202. doi:10.1049/cp:19991018 